\title{
Prevalence of amyotrophic lateral sclerosis in the city of Porto Alegre, in Southern Brazil
}

\author{
Prevalência de esclerose lateral amiotrófica na cidade de Porto Alegre, sul do Brasil \\ Eduardo Linden-Junior', Jefferson Becker², Pedro Schestatsky ${ }^{3}$, Francisco Tellechea Rotta ${ }^{4}$, \\ Carlo Domenico Marrone ${ }^{5}$, Irenio Gomes ${ }^{6}$
}

\begin{abstract}
Objective: To determine the prevalence of amyotrophic lateral sclerosis (ALS) in the city of Porto Alegre, Brazil. Method: We conducted an extensive investigation in clinics and hospitals that provide specialized assistance to these patients, contacted neurologists and the regional association of people with ALS. Results: On July 31, 2010, 70 patients were alive and diagnosed with amyotrophic lateral sclerosis. Considering the population living in the city in the same period (1,409,351), the estimated prevalence was 5.0 cases per 100,000 people $(95 \% \mathrm{Cl}$, 3.9-6.2), being higher for men (5.2/100,000 95\% Cl, 3.6-7.2) than for women (4.8/100,000 95\% Cl, 3.4-6.5). The prevalence increased with age peaking in the age group 70-79 years in both genders. Conclusion: The prevalence of ALS in the city of Porto Alegre is similar to that reported in other parts of the world.
\end{abstract}

Keywords: amyotrophic lateral sclerosis, epidemiology, prevalence.

\section{RESUMO}

Objetivo: Determinar a prevalência de esclerose lateral amiotrófica (ELA) no município de Porto Alegre, Brasil. Método: Foi realizada ampla busca em hospitais especializados, contato com neurologistas e com a associação regional dos portadores de ELA para identificar os casos. Resultados: No dia 31 de julho de 2010, 70 pacientes estavam vivos e com diagnóstico de ELA. Considerando a população residente no município no mesmo período (1.409.351), a prevalência estimada foi de 5,0 casos a cada 100.000 pessoas (IC 95\%, 3,9-6,2), sendo maior para os homens (5,2/100.000 IC 95\%, 3,6-7,2) do que para as mulheres (4,8/100.000 IC 95\%, 3,4-6,5). A prevalência aumentou com a idade, atingindo um pico entre os 70 e 79 anos, em ambos os sexos. Conclusão: A prevalência de ELA no município de Porto Alegre é similar à encontrada em outras localidades no mundo.

Palavras-chave: esclerose lateral amiotrófica, epidemiologia, prevalência.

Amyotrophic lateral sclerosis (ALS) is a disorder characterized by degeneration and cell death of neurons in the motor cortex, brainstem and spinal cord ${ }^{1}$. In most cases the cause of the disease is unknown, and it is a usually a sporadic disorder, although about $5 \%$ of cases have a positive family history ${ }^{2}$. ALS is a devastating condition with enormous impact on patients, family members, caregivers and professionals involved in the treatment. It is also one of the most intriguing diseases regarding the understanding of its pathogenesis ${ }^{3}$.

The degenerative process of this disease has a complex and multifactorial etiology ${ }^{4}$. The current hypotheses about the underlying pathological mechanisms of this disease suggest that there is a complex interaction between the various mechanisms, including genetic factors, oxidative damage, accumulation of intracellular aggregates, mitochondrial dysfunction, axonal transport defects, pathology of glial cells and excitotoxicity ${ }^{5}$.

Except for a few islands located in the western Pacific, it is believed that ALS has a relatively even distribution in the world. However, epidemiological studies have reported a prevalence ranging from 0.8 to 10.32 cases per 100,000 people $^{6-9}$. This variability can be explained by methodological

${ }^{1} \mathrm{PT}, \mathrm{MSc}$, Private Practice, Porto Alegre RS, Brazil;

${ }^{2} \mathrm{MD}, \mathrm{MSc}, \mathrm{PhD}$, Departamento de Neurologia, Pontifícia Universidade Católica do Rio Grande do Sul, Porto Alegre RS, Brazil;

${ }^{3} \mathrm{MD}, \mathrm{MSc}, \mathrm{PhD}$, Departamento de Medicina Interna, Universidade Federal do Rio Grande do Sul, Porto Alegre RS, Brazil;

${ }^{4} \mathrm{MD}$, Departamento de Neurologia, Santa Casa de Porto Alegre, Porto Alegre RS, Brazil;

${ }^{5} \mathrm{MD}$, Departamento de Neurologia, Pontifícia Universidade Católica do Rio Grande do Sul, Porto Alegre RS, Brazil;

${ }^{6} \mathrm{MD}, \mathrm{MSc}$, PhD, Departamento de Neurologia, Pontifícia Universidade Católica do Rio Grande do Sul, Porto Alegre RS, Brazil.

Correspondence: Eduardo Linden Junior; Rua Julio de Castilhos 2270/401; 95600-000 Taquara RS - Brasil; E-mail: eduardolindenjunior@gmail.com

Conflict of Interest: There is no conflict of interest to declare.

Received 26 May 2013; Accepted 07 July 2013. 
differences, variability in diagnostic criteria over time and because several countries such as Brazil do not have adequate systems of disease notification. Incidence studies, which have lower variability, as they can only be conducted under ideal conditions of disease documentation, show a variation between 1.5 and 2.5 cases per 100,000 people per year ${ }^{10}$. Nevertheless, most epidemiological studies are conducted in North America and Europe. So, it is essential to seek information from other parts of the world and thereby better understand the distribution and possible determinants of the disease.

In South America there is little information available about the occurrence of ALS. The first study to identify the incidence and prevalence of ALS in a South American country was recently published ${ }^{11}$. In Brazil, the largest South American country, no study has been conducted so far on the frequency of ALS based on a large population and on El Escorial criteria for amyotrophic lateral sclerosis established in the 1990's.

The present study was aimed to determine the prevalence of ALS in the city of Porto Alegre, Rio Grande do Sul, Brazil, presenting the prevalence by age group and gender.

\section{METHOD}

The research was conducted in the city of Porto Alegre, capital of the State of Rio Grande do Sul, Brazil. According to data of the national census of 2010, the population of Porto Alegre was 1,409,351 people living in an area of $476.3\left(\mathrm{~km}^{2}\right)^{12}$. The study was approved by PUCRS' Ethic Research Committee under number 11/05452. The study included all patients identified with a diagnosis of definite, probable or possible ALS, according to El Escorial criteria, who remained alive on July 31, 2010.

In order to identify the cases of ALS an extensive search using three simultaneous strategies was performed from July to October 2010. All local clinics and hospitals that provide specialized assistance to patients with neuromuscular disorders were contacted and provided the requested information on the patients diagnosed with ALS and followed-up from 2009 to 2010. All neurologists or neurosurgeons were contacted through a message of the Rio Grande do Sul's Society of Neurology and Neurosurgery requesting information from patients diagnosed with ALS followed up from 2009 to 2010. Finally, the regional association of people with amyotrophic lateral sclerosis was contacted and also provided information on patients registered in the referred years.

The data collected were stored in an Access database and analysis was made using SPSS (version 17). The prevalence was calculated by the number of cases of patients diagnosed with ALS that were alive on July 31, 2010, divided by the total population of the study city. For inference of such data to other similar cities of the region, random variation was calculated for the study sample using a 95\% confidence interval. Prevalence stratified by gender and age was also calculated.

\section{RESULTS}

70 individuals (34 men and 36 women) who remained alive on July 31, 2010 were identified with a diagnosis of definite, probable or possible ALS, according to El Escorial criteria. The age ranged from 31 to 93 years, with an average of 61.5 years, 59.3 for men and 63.6 for women.

The prevalence was 5.0 cases per 100,000 people, considering the population living in the city of Porto Alegre in 2010, being slightly higher for men, with a male/female ratio of 1.08:1. Table shows the total prevalence and the prevalence stratified by gender, with the respective confidence intervals.

Figure 1 shows the prevalence of ALS by age group and gender. The prevalence of ALS was zero until the fourth decade of life. From then on, the prevalence of ALS increased with the age, peaking in the age group 70-79 years $(30.5 / 100,000)$, both for men $(25.0 / 100,000)$ and women $(33.7 / 100,000)$, and decreasing in the 80 years or over age group $(11.5 / 100,000)$. In women, the increase in prevalence was steady from 30 to 69 years (ranging between 0.9 and 9.1/100,000), followed by a

Table. Prevalence of amyotrophic lateral sclerosis by gender and total in the city of Porto Alegre, Brazil.

\begin{tabular}{lccc}
\hline Population & $\mathrm{N}$ & $\begin{array}{c}\text { Prevalence } \\
(/ 100,000 \text { persons })\end{array}$ & $95 \% \mathrm{Cl}$ \\
\hline $\begin{array}{l}\text { Men } \\
653,787\end{array}$ & 34 & 5.2 & $3.6-7.2$ \\
$\begin{array}{l}\text { Women } \\
755,564\end{array}$ & 36 & 4.8 & $3.4-6.5$ \\
$\begin{array}{l}\text { Total } \\
1,409,351\end{array}$ & 70 & 5.0 & $3.9-6.2$ \\
\hline
\end{tabular}

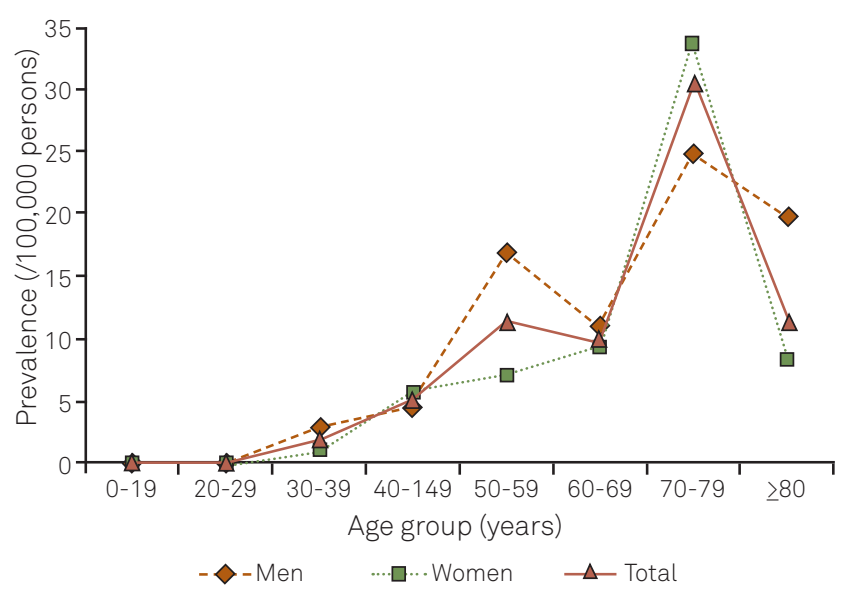

Figure 1. Prevalence of amyotrophic lateral sclerosis by age group and gender in the city of Porto Alegre, Brazil. 
rapid increase between 70 and 79 years. In men, on the other hand, there was a sudden increase in the age group of 50-59 years $(17.0 / 100,000)$, followed by a decline in the age group of 60 - 69 years $(10.9 / 100,000)$, and peaking in the age group of 70-79 years.

\section{DISCUSSION}

This study is the first to estimate the prevalence of ALS in Brazil. It is also one of the first studies of its kind in Latin America. Therefore, an extensive investigation of ALS cases in specialized centers was performed, including contact with neurologists and also through the regional association of people with amyotrophic lateral sclerosis, which is very active in the region. Thus, one strength of the study is the probable identification of all patients diagnosed with ALS and who were alive in the study period.

We found that the prevalence of ALS in the city of Porto Alegre, Brazil, is currently 5.0 cases per 100,000 people. The estimated prevalence in our study was close to the prevalence reported for the city of Jefferson in the USA $(3.9 / 100,000)^{13}$, in Modena, Italy $(4.02 / 100,000)^{8}$, in the Republic of Ireland $(4.7 / 100,000)^{14}$, in Ontario, Canada $(4.9 / 100,000)^{15}$ and in southeast England $(4.91 / 100,000)^{16}$. On the other hand, our estimated prevalence is higher than the prevalence of ALS reported in Isfahan, Iran $(1.57 / 100,000)^{17}$, in Uruguay $(1.9 / 100,000)^{11}$ and in Hong Kong, China $(3.04 / 100,000)^{18}$, and lower than the prevalence of ALS reported in Italy $(7.89 / 100,000)^{19}$ and in the Netherlands $(10.32 / 100,000)^{9}$.

In our analysis of the results by gender, we found a higher prevalence of ALS for men $(5.2 / 100,000)$ compared to women $(4.8 / 100,000)$. However, this difference is very small, with a male/female ratio of 1.08:1. Several studies have reported a higher prevalence of ALS in men. Studies conducted in France, Italy, Japan, the United States and India reported male/female ratios ranging from 1.05:1 to 3.0:19-23.

In our study, the prevalence of ALS in women and men increased with age, with a peak of 25.0 cases per 100,000 people for men and 33.7 cases per 100,000 people for women, in the age group 70-79 years, followed by a decline in the 80 years or over age group. These findings are consistent with studies carried out in the Netherlands ${ }^{9}$.

In the 80 years or over age group there was a decline in the prevalence of ALS for both genders (19.9/100,000 for men and 8.1/100,000 for women). However, despite the decline in the prevalence in this age group, the values are still relatively high. In a study conducted in Scotland by Forbes et al., aimed to describe the clinical and epidemiological characteristics of patients with ALS over 80 years, the findings showed that these individuals had lower survival rate at onset of symptoms compared to younger patients, and the incidence was higher in men than in women ${ }^{24}$.

In conclusion, from the results, we can infer that the prevalence of ALS is around 5 cases per 100,000 people in the Southern region of Brazil, and perhaps also, it represents the Southern region of the country. We do not know, however, if the Center-West, North and North-East regions of Brazil have the same prevalence of the disease, since it presents different sociodemographic and health characteristics. Further epidemiological studies are needed in the referred regions. We believe, however, that our findings corroborate the hypothesis of a very similar distribution in different geographical regions, since Brazil is a developing country with a recent and rapid demographic transition, where the occurrence of the disease was similar to the one described in developed countries, which have also a different epidemiological profile.

\section{References}

1. Wijesekera LC, Leigh PN. Amyotrophic lateral sclerosis. Orphanet J Rare Dis 2009;4:1-22.

2. Byrne S, Walsh C, Lynch C, et al. Rate of familial amyotrophic lateral sclerosis: a systematic review and meta-analysis.J Neurol Neurosurg Psychiatry 2011;82:623-627.

3. Mitchell JD, Borasio GD. Amyotrophic lateral sclerosis. Lancet 2007;369:2031-2041.

4. Shaw PJ. Molecular and cellular pathways of neurodegeneration in motor neurone disease.J Neurol Neurosurg Psychiatry 2005;76:1046-1057.

5. Rothstein JD. Current hypotheses for the urderlying biology of amyotrophic lateral sclerosis. Ann Neurol 2009;65(Suppl):S3-S9.

6. Chancellor AM, Warlow CP. Adult onset motor neuron disease: worldwide mortality, incidence and distribution since 1950. J Neurol Neurosurg Psychiatry 1992;55:1106-1115.

7. Román GC. Neuroepidemiology of amyotrophic lateral sclerosis: clues to aetiology and pathogenesis. J Neurol Neurosurg Psychiatry 1996;61:131-137.
Mandrioli J, Faglioni P, Merelli E, et al. The epidemiology of ALS in Modena, Italy. Neurology 2003;60:683-689.

9. Huisman MHB, Jong SW, Doormaal PTC, et al. Population based epidemiology of amyotrophic lateral sclerosis using capture-recapture methodology. J Neurol Neurosurg Psychiatry 2011;82:1165-1170.

10. Logroscino G, Traynor BJ, Hardiman O, et al. Descriptive epidemiology of amyotrophic lateral sclerosis: new evidence and unsolved issues.J Neurol Neurosurg Psychiatry 2008:79:6-11.

11. Vázquez MC, Ketzoián C, Legnani C, et al. Incidence and prevalence of amyotrophic lateral sclerosis in Uruguay: a population-based study. Neuroepidemiology 2008;30:105-111.

12. IBGE. Sinopse censo 2010 (online). Available at: http://www.ibge.gov.br. Accessed: December 23, 2010.

13. Turabelidze G, Zhu B, Schootman M, et al. An epidemiologic investigation of amyotrophic lateral sclerosis in Jefferson County, Missouri, 1998-2002. Neurotoxicology 2008;29:81-86. 
14. Traynor BJ, Codd MB, Corr B, et al. Incidence and prevalence of ALS in Ireland, 1995-1997: a population-based study. Neurology 1999;52:504-509.

15. Hudson AJ, Davenport A, Hader WJ. The incidence of amyotrophic lateral sclerosis in southwestern Ontario, Canada. Neurology 1986;36:1524-1528.

16. Abhinav K, Stanton B, Johnston C, et al. Amyotrophic lateral sclerosis in southeast England: a population-based study. Neuroepidemiology 2007;29:44-48

17. Sajjadi M, Etemadifar M, Nemati A, et al. Epidemiology of amyotrophic lateral sclerosis in Isfahan, Iran. Eur J Neurol 2010;17:984-989.

18. Fong GCY, Cheng TS, Lam K, et al. An epidemiological study of motor neuron disease in Hong Kong. Amyotroph Lateral Scler 2005;6:164-168.

19. Chiò A, Mora G, Calvo A, et al. Epidemiology of ALS in Italy. Neurology 2009;72:725-731.
20. Marin B, Gil J, Preux PM, et al. Incidence of amyotrophic lateral sclerosis in the Limousin region of France, 1997-2007. Amyotroph Lateral Scler 2009;10:216-220.

21. Atsuta N, Watanabe $\mathrm{H}$, Ito $\mathrm{M}$, et al. Age at onset influences on wideranged clinical features of sporadic amyotrophic lateral sclerosis. $J$ Neurol Sci 2009;276:163-169.

22. Stambler N, Charatan M, Cedarbaum JM. Prognostic indicators of survival in ALS. Neurology 1998;50:66-72.

23. Nalini A, Thennarasu K, Gourie-Devi M, et al. Clinical characteristics and survival pattern of 1153 patients with amyotrophic lateral sclerosis: experience over 30 years from India. J Neurol Sci 2008;272:60-70

24. Forbes RB, Colville S, Swingler RJ. The epidemiology of amyotrophic lateral sclerosis (ALS/MND) in people aged 80 or over. Age Ageing 2004;33:131-134. 